\title{
Health geography and the 'performative' turn: making space for the audio-visual in ethnographic health research.
}

\begin{abstract}
The purpose of this paper is to critically reflect on the added value of video in ethnographic research that seeks to understand peoples' lived experiences of health and place. Of particular interest is the potential for video to elicit the embodied, multisensory and relational nature of people's place experiences that are the focus of much recent health geography research. We draw on our experiences of using video in an ethnographic study that sought to explore the experiences of people with intellectual disabilities engaged in nature based (or 'green care') therapeutic interventions for health and wellbeing. We argue that video has the potential to capture aspects of people's wellbeing experiences that may be lost using other methods, such as observational field noting. Consideration is also given to how researchers using video methods should seek to (re)present people's wellbeing experiences, as well as the practical and ethical challenges that this approach has for those working in the field of health geography.
\end{abstract}

\section{Keywords}

Video ethnography; qualitative methods; health geography; non-representational theory; care farming; intellectual disability.

\section{Introduction}

Geographers with a broad interest in health and care have been turning to 'vitalist' ontologies as a means of exploring the multiplicity of ways in which (ill)health manifests, presents or feels (Andrews, 2018). An engagement with new materialist thought, post-phenomenologist stances and non-representational theories therefore encourages health geographers to focus on the relational, affective and multi-sensory experiences of health in place, and ways in which these place experiences are actively performed (Bell et al, 2017). In this vein, recent research has sought to elucidate the more immediate, momentary and sensory aspects of people's therapeutic landscape encounters. These are what Andrews et al (2014) describe as the non-representational or 'basic ingredients' of wellbeing, the coming together of human and non-human bodies as a series of powerful sensory happenings.

This particular approach encourages health geographers to focus on the different relationships that are enacted within different spaces and the various subjects and objects that comprise 'health-giving' assemblages. Such developments therefore seek to circumvent health geography's on-going commitment 
to a broadly 'representational' or social constructivist paradigm, and corresponding attempts to discover the representations, meanings, attachments and identities associated with specific localities (Andrews et al., 2014; Andrews \& Moon, 2005). Indeed, while these endeavours have done much to demonstrate the importance of place for health, they have tended to overlook 'the networked, emerging, physical, sensory atmospheric energetic performed and moving nature of health in place' (Andrews, 2018 pp. 18).

Recent health geography research within the 'performative turn' has tended to focus on qualitative explorations of the processes through which places are co-constructed and emphasise the dynamic, fluid therapeutic and relational aspects of health within a variety of settings (Andrews and Moon, 2005). The specific methods used for these endeavours have been wide ranging, and include progressive ethnographies (e.g. Justesen et al, 2014), 'lively' interviews (e.g. Dean, 2016) and methods using new and innovative technologies (e.g. Bell, 2015; Spinney, 2015). However, the use of video methods in health geography remains relatively uncommon, with only a handful of studies using audio-visual media in their research (e.g. Simpson, 2017; Spinney, 2015).

Yet elsewhere the use of video has shown real potential. For example, Simpson's (2014) geographies of street performance or Pratchett's (2012) video ethnography of taxidermy both serve to illustrate in powerful and evocative ways how video can enable geographies to explore embodied practice, everyday encounters and multi-sensory experience. However, these endeavours do not specifically focus on health. Specifically, the ways in which health presents or feels within everyday contexts or environments. The use of video has also shown much promise in health care research. For example, Carroll's (2009) or Forsyth's (2009) video ethnographies of hospital based settings demonstrate how video methods can be an engaging and empowering visual medium for doing qualitative health research that seeks include the views and experiences of both clinicians and patients. However, these studies do not specifically focus on place, specifically the way in which particular environments (in this case the hospital setting) shapes people's experience of health in complex and varied ways.

Drawing these different strands together, the purpose of this paper is to critically reflect on the added value of video in ethnographic research that seeks to understand people's lived and embodied experiences of health and place. Of particular interest is the potential for video to elicit the embodied, multisensory and wholly relational nature of people's place experiences that are the focus of much recent health geography research. 
In order to discuss the benefits and limitations of video method, we draw on our experiences of using video in an ethnographic study that sought to explore the experiences of people with intellectual disabilities engaged in nature based (or 'green care') therapeutic interventions for health and wellbeing. We argue that video has the potential to capture aspects of people's wellbeing experiences that may be lost using other methods, such as observational field noting. Consideration is also given to how researchers using video methods should seek to (re)present people's wellbeing experiences, as well as the practical and ethical challenges that this approach has for those working in the field of health geography.

\section{Doing place-based video research: an ethnographic case study}

The empirical research which is the focus for this paper, involved ethnographic work conducted with people with intellectual disabilities engaged in care farming activities for health and wellbeing. Care farming is defined as the use of commercial farms or agricultural landscapes to provide health (both physical and mental), social or educational benefits through farming related activities (Hine, Peacock and Pretty, 2008). Care farming is therefore situated within the broader 'green care' movement, a collective term for activities that utilise plants, animals and landscapes to create interventions to improve health and wellbeing.

Three care farm organisations delivering green care services to people with intellectual disabilities were recruited to participate in the research. The study adopted an in-depth and intensive 'case study' approach where individuals were viewed as the 'case studies'. Case study participants were selected on the basis that they had recently been enrolled on a care farming programme and were identified as having an intellectual disability. Seven case study participants were recruited in total, each of whom attended a care farm between 1 and 4 days per week. The study also recruited additional individuals that made up case study participants' wider networks of professional and personal relationships. This included staff based at the care farms that participants attended as well as family members and/or paid support workers (13 additional participants in total).

Data was collated longitudinally over a period of 10 months to ascertain the impacts of care farming on the lives of people with intellectual disabilities over a sustained period of time. The fieldwork phase of the study comprised of two rounds of data collection. The first took place from July 2014 to October 2014, followed by a repeat round approximately six months later, from January to April 2015. A range of qualitative ethnographic methods of data collection was used for each case study, including participant 
observation, qualitative interviews and ethnographic video, through which to explore participants' multisensory place experiences.

A comprehensive outline of the methods used and ethics protocol are detailed elsewhere 2019a), but for the purposes of this paper we would like to focus on the video element of the study, which consisted of two phases.

\section{Phase 1: video data collection}

Video-data was collated over a period of 10 months (using a compact NXCAM HD camcorder). Time was spent with each of the case study participants at the care farm they attended (approx. 6 days with each individual), video recording them as they went about their normal daily activities. The purpose of this part of the research was to capture participants' embodied and multi-sensory experiences while at these farm settings. It also provided a means through which to understand the meanings that people attached to these experiences and how they contributed (or not) to wellbeing. Following the work of contemporary visual ethnographers (e.g. Pink, 2001; 2014, Grasseni, 2004) the researcher sought to ensure that the video ethnographic sessions were as collaborative and participatory as possible and that the audio-visual data collated reflected the intentionalities of both the researcher and participants. To this end, participants were also encouraged to 'direct' the content of these videos in ways that reflected their own interests and preferences and were frequently consulted about filming progress, editing options and future activities.

\section{Phase 2: visual elicitation interviews}

Participants were invited to take part in two qualitative visual elicitation interviews. These took place soon after the video data collection sessions (within approx. 1-2 weeks) in order to ensure that participants had relatively fresh memories of the events, activities or social interactions being presented to them. The primary purpose of presenting participants with edited versions of the video footage was to provide them with certain visual cues designed to guide the interview process, prompt discussion and provide a basis for reflection. The first stage of the interview involved inviting participants to watch edited versions of their video footage. Selected scenes included those where an individual was perceived by the researcher to be gaining some form of enjoyment or benefit from participation in a particular activity, certain events that may have constituted a negative experience for participants, or scenes that evidenced a change in behaviour or relational capabilities. Participants were asked to describe in their own words what was 
taking place, how they felt emotionally during these scenes and whether (and in what ways) care farming had helped them to think and feel differently.

\section{Ethics}

The study was reviewed by the Faculty of Health and Medicine research ethics committee and approved by the University Research Ethics committee at _ Permission to use participants' identifiable visual images was sought prior to their usage in publications. This required the researcher to ensure that participants with learning disabilities fully understood what the implications of identifiable images being disseminated might be, and that consent to use visual images in this way was voluntary and fully informed. This was achieved by presenting the information in an accessible format where necessary (i.e. easy read information sheets and consent forms) through role-play and via video demonstrations (using participants actual data). Informed consent was sought both prior to commencement of the research and at the point of dissemination. Participants were given pseudonyms at their request.

In the remainder of this paper, we focus on the video element of this ethnographic study. Specifically, we discuss the strengths and challenges of this approach, and what video as an ethnographic method has to offer researchers working in the field of health geography.

\section{Capturing 'wellbeing happenings'}

In this visual ethnographic study, moving visual imagery provided a means through which to capture the visual look of these agricultural landscapes in ways that are more closely aligned with how perception occurs in action. During fieldwork the researcher would often use the video recorder while moving through the landscape to capture events and as they occurred in real-time. The high definition footage was, therefore, able to capture not only formal properties of landscape (e.g. position in space, colour or structural form) but also how these various features were experienced from the perspective of the moving subject. 


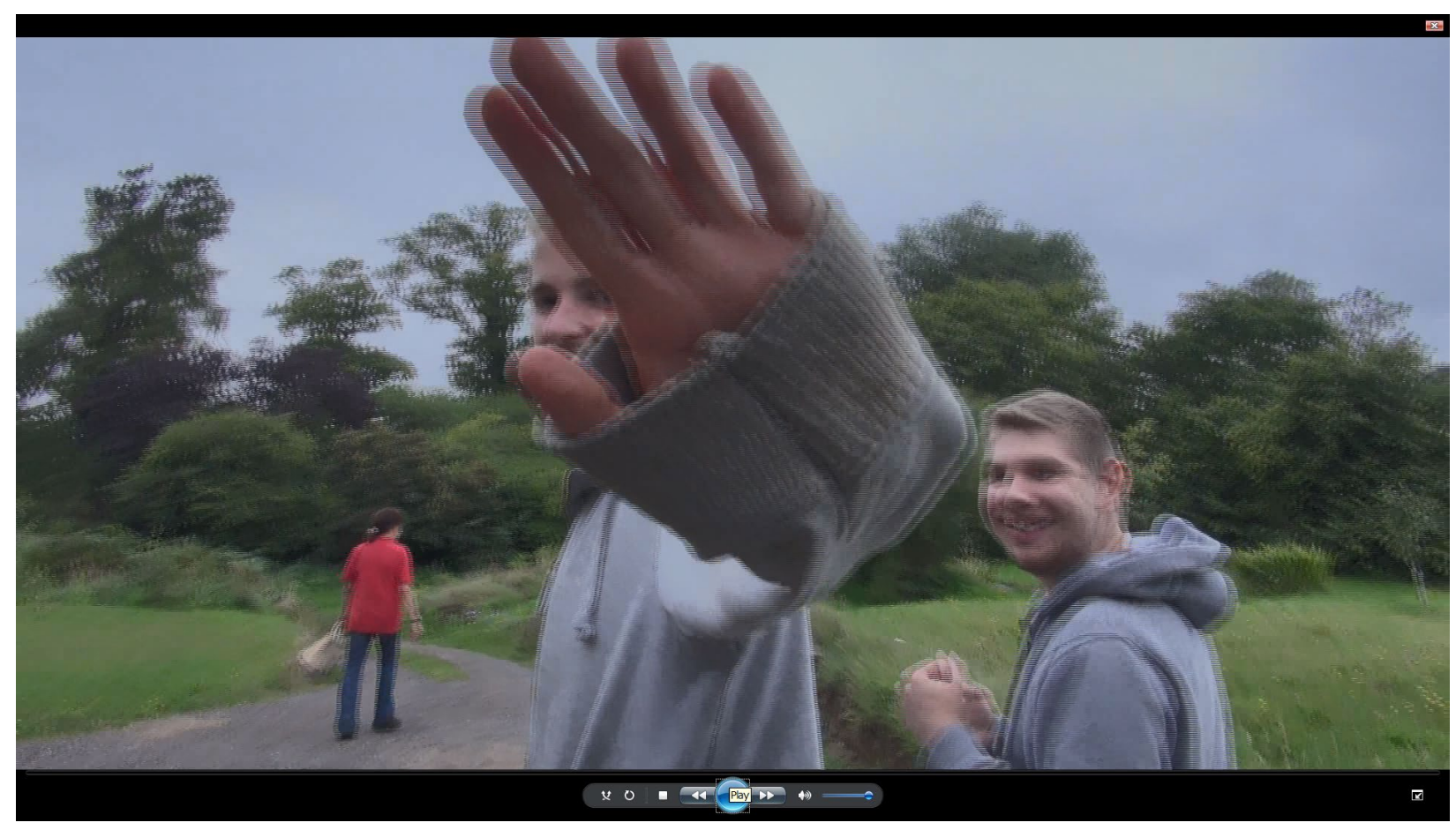

Figure 1. Video clips showing 'movement' [youtube link: https://youtu.be/PnISWAzwZcs ]

This perspective therefore seeks to move beyond the perceived groundlessness that Ingold (2004) ascribes to western ocularcentric studies of landscape, to consider multisensory and embodied experience (Forsyth et al., 2013). Similarly, much of the recent health geography literature is concerned not only with the visual or 'scenic' properties of landscape but on what all the senses notice, and how these multi-sensory experiences are interpreted and represented (e.g. Bell et al, 2019; Doughty, 2013; Gorman, 2017).

While video is essentially an audio-visual medium, it is argued that video, especially good quality and high definition footage, has the potential to evoke olfactory and tactile sensory perceptions as well (Garrett, 2015). In this study, digital video was a valuable tool through which to engage the full sensuality of participants' lived experiences, that is, the sights, sounds, smells, tastes and tactile sensations that make up the character of a place. Watching the videos back helped the researcher to focus on the complex material interactions between bodies and to access the sensed or felt qualities of those interactions, such as the feel of a cold winter's day or touch of an animal's fur. 


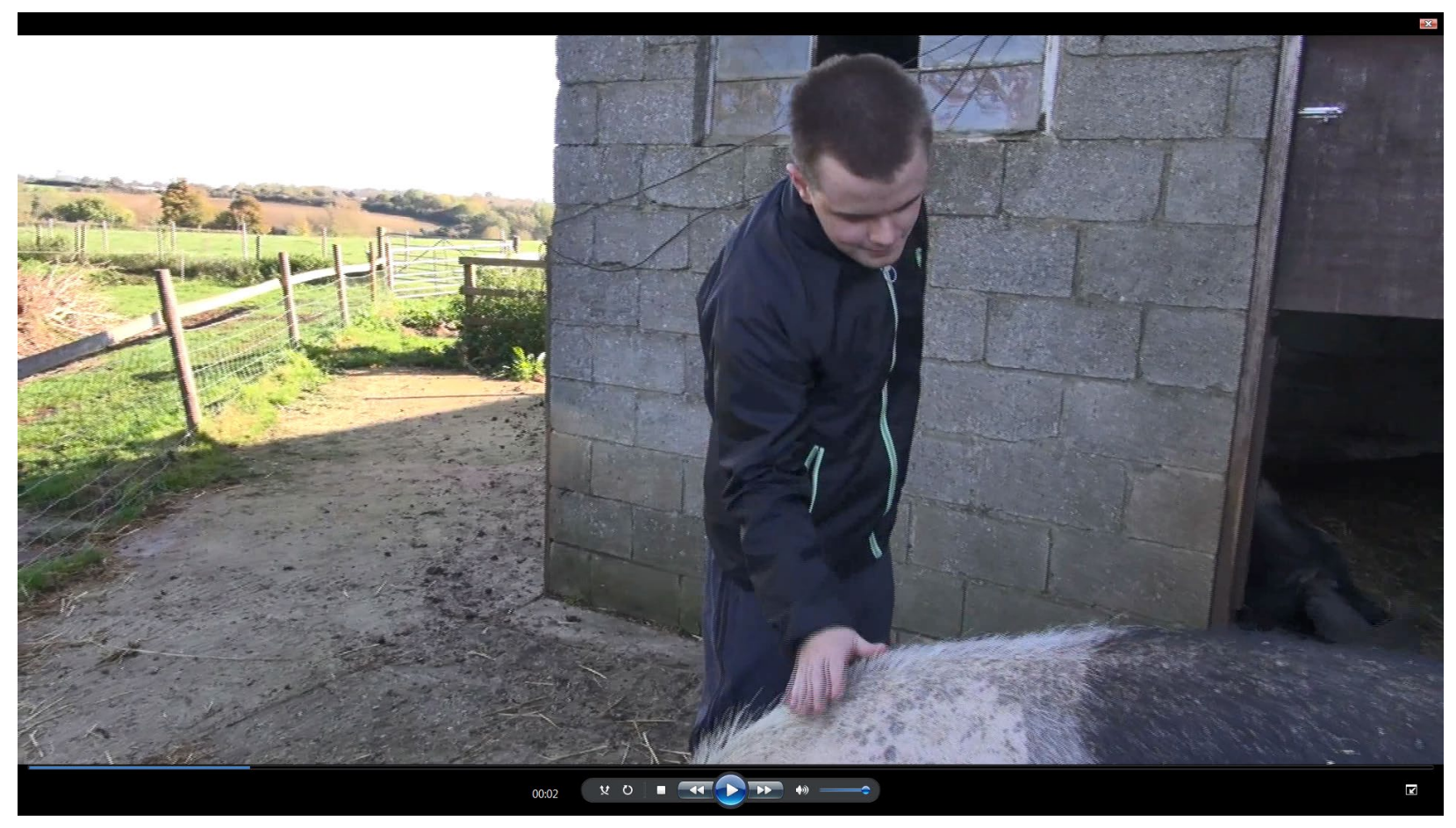

Figure 2. Video clip of Jed stroking one of the farm pigs [youtube link: https://youtu.be/OITZLasaptw ]

In this video clip Jed is in the pig enclosure. Sally (a female pig) is eating from a container that Jed has just set down in front of her. Jed watches her eat for a moment before he approaches her carefully. He begins to stroke her back. Sally does not appear to notice Jed's touch and continues to eat. Jed carefully runs his hand along her rough and hairy skin, removing bits of straw and sawdust as he does so. 'Are you getting bits out of her fur?' I ask as I stand there filming. Jed nods his head in response and smiles. (Researcher, video commentary)

Collating audio-visual data can, therefore, encourage geographers interested in the relationship between health and place to critically reflect on the way in which touching encounters like those depicted above, can create affective registers in and through which wellbeing is enabled to emerge. Of course, we are not claiming here that video was able to directly record things like smell or touch, merely that the audio-visual data provided a route through which the researcher could empathise with participants' multisensory and embodied experiences beyond the aural or visual (Pink, 2001). 


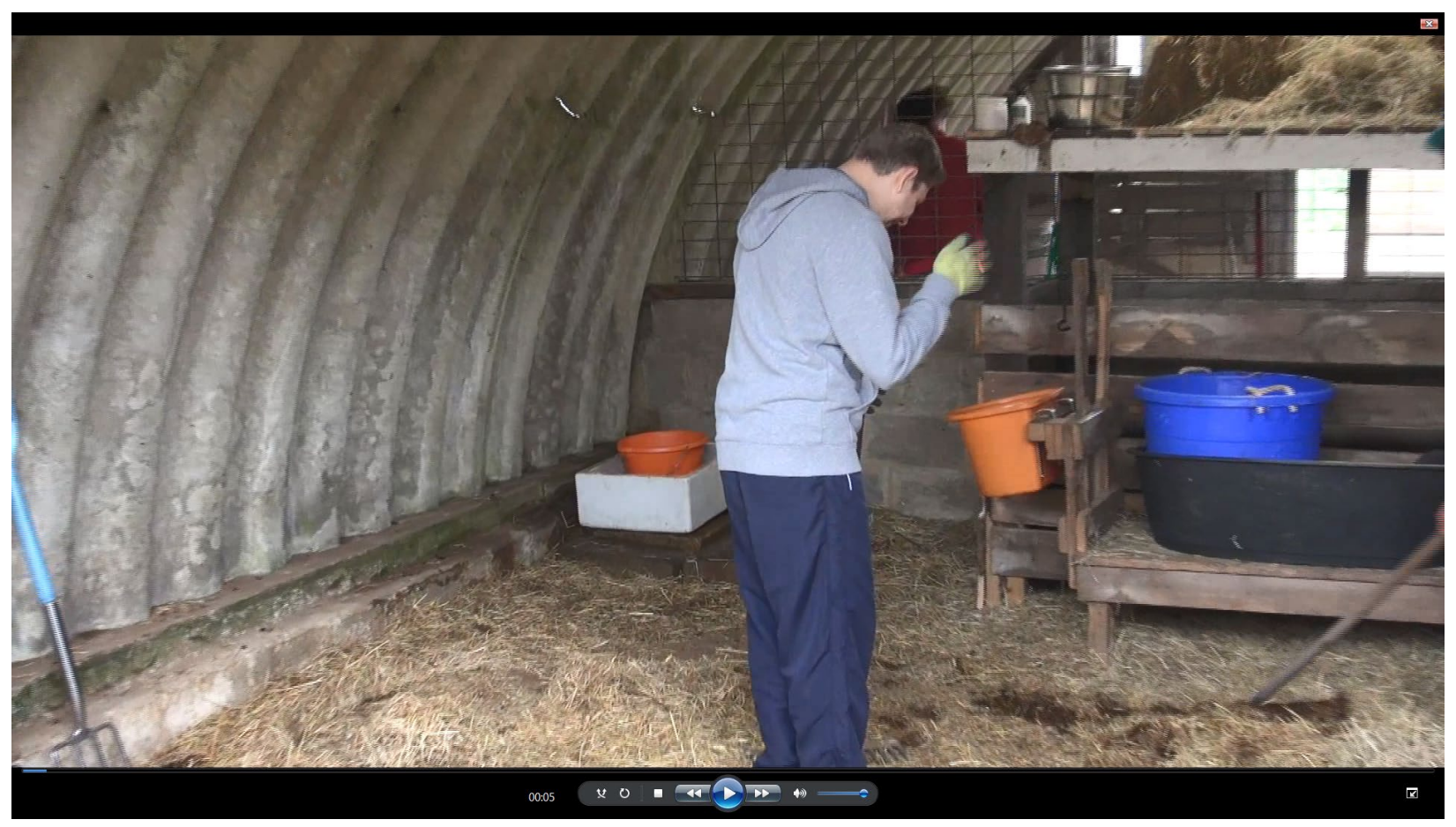

Figure 3. Video clip of James in the goat enclosure [youtube link: https://youtu. be/AeprcUHExA4 ]

James and Jack are cleaning out the goat enclosure. They are using rakes to sweep the dirty straw into a pile in the middle of the room. As they work they can be heard commenting on the smell with exclamations like 'Urgh' and 'phwoar'! As James begins to rake up a particularly soiled patch of straw, he has to stop for a moment. He then waves his hand across his nose to indicate his displeasure and begins to laugh (Researcher, video commentary).

As Figure 3 demonstrates, while it is not possible for a video camera to record smell directly video can record how people respond bodily to particular smell encounters. For example, by attending to the way in which an individual moves from the smell in question, shakes their head or holds their nose. In this way, the collation of audio-visual material can serve to illuminate how embodied engagements with particular smellscapes can create (non)/therapeutic encounters with place (Gorman, 2017).

Others have noted that video is a useful geographic research tool because of its ability to capture movement and the flux and flow of encounter (Garett, 2010, p. 378). Indeed, the use of a video camera in research is arguably a most effective means of recording the experiential stream of time in the field, as well as the various tempos and rhythms of everyday life (McHugh, 2000). In our research, video allowed us to record the way in which participants engaged with and moved through the farm landscape. For example, close analysis of certain video clips enabled the researcher to observe the fluidity and purposiveness of participants' movements as they became increasingly more accustomed to a particular 
activity or environment. While others made the researcher cognisant of the way in which a sudden noise (e.g. a chicken clucking) or new and unfamiliar task had a 'slowing down' effect that inhibited a participants' capacity to act, as evidenced by a sudden lack of engagement or physical withdrawal from an activity or social situation.

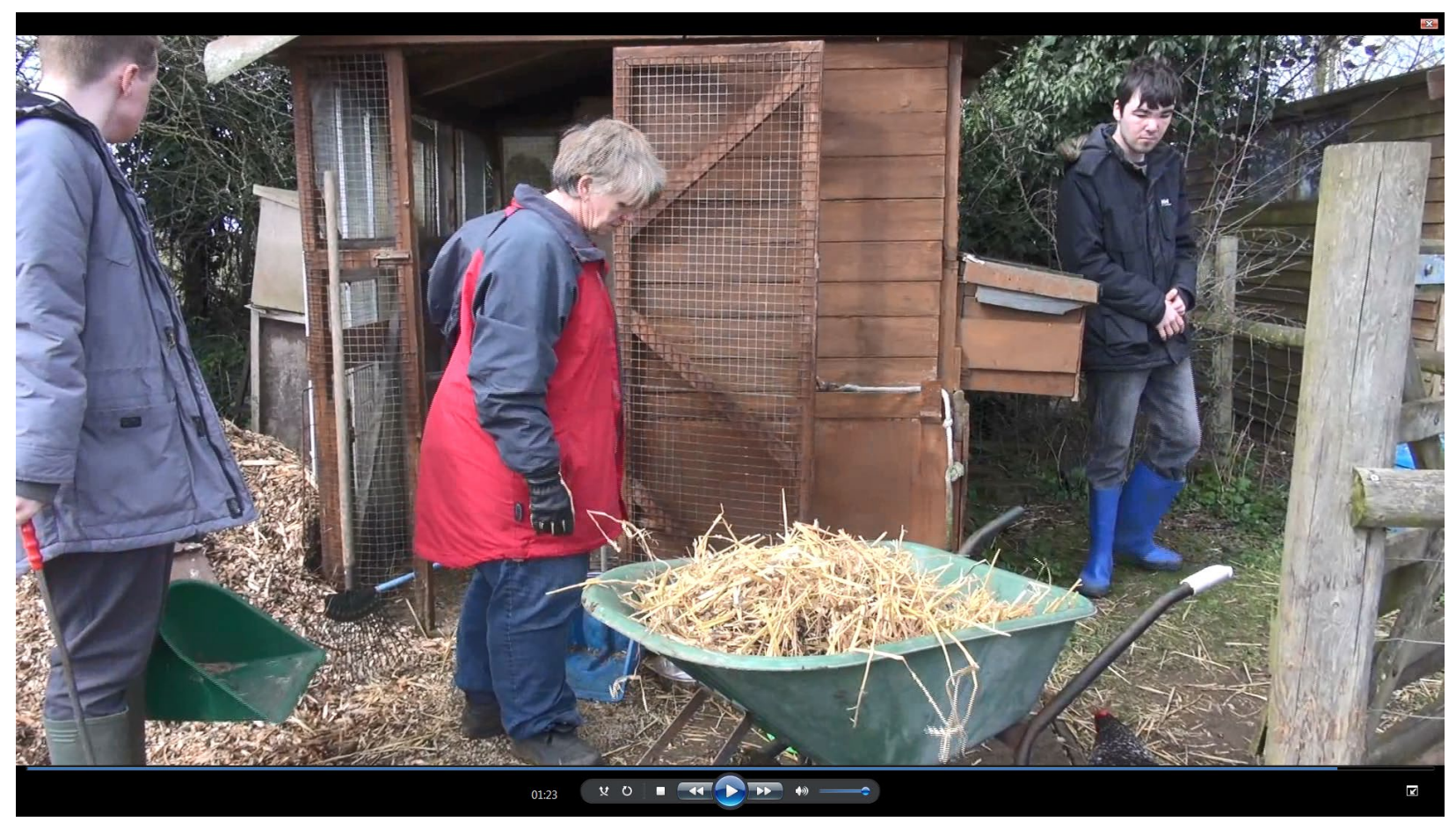

Figure 4. Eliot and the 'noisy' chickens [youtube link: https://youtu.be/-w5VIE4yBwY]

In this video, the chickens are making a lot of noise and this appears to be making Eliot quite anxious. He repeatedly glances towards the chicken coop and begins to shift from one foot to another in an agitated fashion. Eliot then stops what he is doing and moves to the far corner of the pen, seemingly unable to complete the task at hand (Researcher, video commentary).

As Andrews et al (2014) observe, affective moments like these begin at the atomic or molecular level. In this video clip, the movement of air molecules (sound) creates an atmosphere that is both antagonistic and disruptive. This demonstrates how sounds generate affective forces that impact on human bodies in varied ways (Doughty, Duffy and Harada, 2016). Not only is it possible to hear the chicken clucking throughout this audio-visual recording, but also to see its physical effects on Eliot and the way in which this negatively impacted on his day. When analysed and interpreted in this way, video data therefore offers a novel means of illuminating the ways in which affect is felt between individuals, either positively or negatively, and how this bears on their capacity for engagement. 
Video as ethnographic method can, therefore, provide 'lively materials' (Lorimer, 2010) for subsequent presentation and evocation, and offer a novel means of illuminating the way in which affective encounters are felt between bodies (both human and non-human). Indeed, many of these experiential encounters were fleeting and momentary, and may have been lost using other methods, such as observational field noting. What is more, while these affective and more momentary elements of wellbeing may not be noted during the time of filming, they may present themselves as significant upon reviewing the data.

\section{Analysing videos: Re(presenting) experience.}

For this study, digital video was a valuable tool through which to engage the full sensuality of participants' experiences, that is, the sights, sounds, smells, tastes and tactile sensations that characterise interactions between people and places. Watching the videos back helped the researcher to access the sensed or felt qualities of those interactions and the way in which these experiences facilitated (or inhibited) therapeutic gain. By attending to the more immediate and momentary aspects of wellbeing we were therefore able to elicit some important aspects of participants' experiences, that may have been lost using other methodological approaches. Certainly, the care farm setting came to represent an important space of wellbeing for participants. Indeed, participants (as well as staff, parents and carers) generally described care farming in positive terms and participants derived numerous benefits from engaging in these kinds of activities. Yet attending to participants' 'base level' sense encounters revealed a rather more complicated picture. For example, re-watching the videos made it apparent that participants did not always enjoy spending time outdoors, whilst others experienced certain farm sounds, smells and tastes as unpleasant or unnerving. These findings therefore suggest that we should be cautious when making generalised claims about the therapeutic benefits of being in 'natural environments' and supports other research on therapeutic landscapes, which suggests that being outdoors does not always constitute a positive experience for people (Milligan and Bingley 2007; Conradson 2005).

One obvious criticism of attempts to capture or analyse affective or immediate experience, concerns the fact that any kind of reflection on a pre-cognitive feeling state ends with a fully cognitive interpretation of that state, influenced by the beliefs, history and socio-cultural position of the person doing the interpreting. In other words, attempts to expose a 'vibrant sensory happening' signify an attempt to represent that which is non-representational. This presents something of a paradox, since no matter how creative our mode of delivery, moves to represent the non-representational aspects of life will inevitably 'deaden' it or miss(represent) it to some degree (Andrews, Chen and Myers, 2014). 
Of course, by reflecting on affective events in this way we inevitably lost some of the pre-conscious or non-representational aspects of wellbeing that was our aim to capture. However, video recording these 'wellbeing happenings' as they unfold in real-time space (now forever visible for others to witness and interpret) can go some way in preserving something of the vibrancy or immediacy of the interactions described. As Simpson (2012) observes, this is not to say that video somehow offers a kind of detached or objective means of capturing affect. Merely that video has the potential to present to the viewer certain affective encounters that are relevant for health, and until now have been largely ignored or 'regarded as barely relevant background' (Andrews, 2014, p. 339).

Whilst video has the potential to evoke in the viewer an awareness of the various affective forces that are relevant to wellbeing, video does not (and cannot) offer the researcher unmediated access to people's lived experiences. A video recording is just that, a recording. It presents the viewer with a representation of experience, not experience itself. Rather than viewing video as a means of recording human experience in any direct or objective sense, we therefore follow Pink (2001) in arguing that 'reality is subjective and is known only as it is experienced by individuals' (ibid, p. 36). This approach therefore acknowledges that videos are interpreted in different ways and by different people at different points in the research process (Mitchell, 2000). Data analysis was not, therefore, a simple matter of interpreting the visual content of the video data, but involved examining how different producers and viewers of these images give subjective meaning to their content and form (Trena, Paulus and Dempster, 2014). To this end, inviting participants to directly engage with the visual data during their qualitative interviews helped to deepen the researcher's own understanding when analysing these videos, and significantly influenced how we chose to represent the experiences of those who participated in the research

\section{Video in health geography research: ethical and practical challenges}

Research in the field of health geography often seeks to understand the place experiences of those who may be considered marginalised, oppressed and/or underrepresented in research (e.g. Bell et al, 2019;

; Hall \& Power, 2017; Curtis et al, 2009). The value of using participatory video methods to understand the experiences of marginalised groups within a range of contexts are becoming more widely understood (e.g. Milne et al, 2012; Kindon, 2003; Sitter, 2015). To this end, it is argued that participatory video can increase agency and disrupt hierarchies of power by giving 'voice' to certain marginalised groups, such as young people or people with disabilities (Wilson \& Milne, 2016). 
In a recent paper ( we sought to critically explore some of the participatory processes involved in making ethnographic videos, and the benefits and challenges of using this method with people with learning disabilities. We argue that video methods are potentially more accessible than traditional qualitative methods (e.g. interviews or focus groups) and can help people to feel more empowered when participating in qualitative research and to feel more confident about communicating their experiences. Indeed, cameras, video and T.V. play an important role in our modern society and as such, are accessible to many different people. We recognise, however, the tensions inherent in using a method that is externally imported and/or controlled by the researcher (Walsh, 2016). In our study, it was the researcher who had control of the video recording technology. This was largely motivated by a desire to include participants themselves in these ethnographic videos. While we sought these filmmaking sessions to be as collaborative as possible, the participatory process could arguably have been enhanced had participants been allowed to do some filming of their own. Indeed, the people who took part in the care farming study knew how to use video recording technology and understood its purpose, and a number of participants had cameras on their smartphones that they regularly used to take photographs or make videos. As Mitchel et al (2016) observe however, allowing research participants to use their own devices to make videos for research purposes creates a host of new ethical dilemmas. Most notably, the potential for participants to create and post films on social media, unmediated by researchers. We therefore agree with Wilson \& Milne (2016) that participatory video methods should not be regarded as an unequivocal means to empowerment and engagement, and encourage health geographers seeking to use video in their research to be mindful of the 'complex messiness' (Kindon, 2016 pp. 449) and inherent tensions that this method presents.

Health geography research happens in many different places, such as, public parks and gardens (e.g. Pitt, 2014) coastal environments (e.g. Bell et al, 2015; Foley \& Kistenmann, 2015) forests and woodlands (Milligan \& Bingley, 2007), as well as the home (Williams, 2002), community centres (e.g. Glover \& Parry, 2009; Butterfield and Martin, 2016) and clinical settings (e.g. Gesler et al, 2004; Curtis et al, 2009, Collins et al, 2016). To this end, it is important for health geographers to think about the potential benefits of using video in their research, relative to the ethical and practical challenges that using such methods might present. In our study, whilst the use of video conferred certain advantages, there were some ethical and practical considerations, which arose during fieldwork. Indeed, while video proved to be an effective research tool when used in the public space of the community farm setting, it became apparent that it would not always be possible or appropriate to replicate this in other places, such as individuals' homes. 
This is because observing and video recording people in their homes, or other more private spaces, has the potential to make people uncomfortable and may, therefore feel too intrusive. These considerations are perhaps all the more relevant when doing research with individuals in clinical settings (such as the hospital or psychiatric ward) or other spaces of care (disabled day centres or residential services) where people are already confronted with the extended gaze of the professional or practitioner in their everyday lives. Indeed, video research works best when it is collaborative, engaging and done in ways that reflect the intentions, preferences and communication styles of the participant. To this end, researchers interested in using video as an ethnographic method must ensure that the environment within which they are working offers an appropriate space for doing collaborative and inclusive visual research.

Finally, the use of video methods raises some important ethical concerns with regards to participant anonymity and confidentiality. This is because much visual material makes the anonymization of individuals or locations problematic, if not impossible. Moving visual images portray clearly identifiable individuals, where these sorts of images can only be anonymised by altering the image in some way so as to obscure participants' identity. As we have argued in this paper, video as an ethnographic method has the potential to portray something additional to text alone. Given this, to tamper with images in ways that obscure certain important details, such as people's facial expressions, makes the purpose of collecting visual data questionable. Obscuring faces affects the viewer's ability to make sense of visual data because faces are necessary to enable us to interpret physical, psychological, social and emotional aspects of individuals (Pink, 2014). Moreover, many people who participate in visual research may actually want to be identified by their visual images (Prosser \& Loxley, 2008). This may be especially relevant for marginalised groups, such as people with disabilities, who advocate for their right to be made visible (Aldridge 2006). It is therefore suggested, that audio-visual material should be presented in its entirety, enabling individuals to be identified with their voluntary and informed consent.

\section{Conclusion}

In this paper, we have sought to share methodological insights gained from a visual ethnographic study that examined the experiences of people with intellectual disabilities engaged in 'green care' activities for health and wellbeing. In doing so, it was our aim to demonstrate the added value of using video in ethnographic research that seeks to understand the sensory, performed and moving nature of health in place (Andrews, 2019). As we have argued, this is an important avenue of exploration for the sub-field of health geography. In using video for these purposes, we suggest that audio-visual media present a novel (and somewhat underexplored) means of eliciting some of the more immediate, fleeting and momentary 
aspects of wellbeing that may be lost using other approaches, such as observational field noting. In making this observation, we do not suppose that video is somehow able to capture people's wellbeing experiences in any 'real' or objective sense. Merely that video has the potential to invoke in the viewer an awareness of the various affective encounters that are relevant for health. Whilst video can be a useful tool for health geography research, when reflecting on our own experiences of using this method, we are keen to stress the need to consider the relative appropriateness of using video, depending on the environment within which one is working and the participant group involved. Related to this point, is the observation that whilst video may be an effective method for capturing the 'here and now' of embodied experience, health geographers should be more cautious when using these methods to build the so-called bigger research picture (Kearns, 2014). Although our place experiences have many felt or physical stages that precede interpretation or representation, it is also important to acknowledge that the shared social and cultural meanings we attach to these experiences are symbolically produced and reproduced over time. To this end, any attempt to document or represent individual corporeal and sensory experience should always be done within a broader sociocultural lens in order to provide a more holistic understanding of social life. Given this, the value of video as an ethnographic method for health geography research may arguably be enhanced when used in conjunction with other methods, such as qualitative interviews or participant observation. In using these methods concurrently we therefore suggest that it is possible to evoke not only the material, embodied and performed aspects of people's therapeutic landscape, but also the more meaning laden processes and structures that are relevant to wellbeing.

\section{References}

Aldridge, J. (2006) 'Picture this: the use of participatory photographic research methods with people with learning disabilities', Disability \& Society, 22(1), pp. 1-17. doi: 10.1080/09687590601056006.

Andrews, G.J. (2018) Non-Representational Theory and Health: The Health in Life Space-Time Revealing. Oxford: Routledge.

Andrews, G. J., Chen, S. and Myers, S. (2014) 'The "taking place" of health and wellbeing: Towards nonrepresentational theory.', Social Science \& Medicine, 108, pp. 210-22. doi:

10.1016/j.socscimed.2014.02.037.

Andrews, G. J. and Moon, G. (2005) 'Space, Place, and the Evidence Base : Part I - An Introduction to Health Geography', Worldviews on Evidence Based Nursing, second quarter (2005). 
Bell, S., Leyshon, C. and Phoenix, C. (2019) 'Negotiating nature's weather worlds in the context of life with sight impairment. Transactions of the Institute of British Geographers (In Press).

Bell, S. L., Foley, R., Houghton, F., Maddrell, A., \& Williams, A. M. (2018). From therapeutic landscapes to healthy spaces, places and practices: A scoping review. Social Science and Medicine, 196(May 2017), 123130. https://doi.org/10.1016/j.socscimed.2017.11.035.

Bell, S., C, Phoenix. and Lovell, R (2015) Seeking everyday wellbeing: the coast as a therapeutic landscape. Social Science and Medicine, 142, pp. 56-67.

Carroll, K. (2014) 'Outsider, insider, alongsider: Examining reflexivity in hospital-based video research', International Journal of Multiple Research Approaches, 3(3), pp. 246-263. doi: 10.5172/mra.3.3.246.

Collins, J., Avey, S. and Lekkas, P. (2016) 'Lost landscapes of healing: the decline of therapeutic mental health landscapes', Landscape Research, 41(6), pp. 664-677.

Curtis, S. et al. (2009) 'New spaces of inpatient care for people with mental illness: A complex "rebirth" of the clinic?', Health \& Place, 15, pp. 340-348.

Dean, J. (2016) Walking in their Shoes: Utilizing go-along interviews to explore participant engagement with local space. In Fenton, N, E., \& Baxter, J. (Eds), Practising qualitative methods in health geographies. London: Routledge.

Doughty, K. (2013) 'Walking together: The embodied and mobile production of a therapeutic landscape', Health \& place, 24, pp. 140-146.

Doughty, K., Duffy, M. and Harada, T. (2016) 'Practices of emotional and affective geographies of sound', Emotion Space and Society, 20, 39-41.

Foley, R. (2011) 'Performing health in place: the holy well as a therapeutic assemblage.', Health \& Place, 17(2), pp. 470-9. doi: 10.1016/j.healthplace.2010.11.014.

Foley, R. and Kistemann, T. (2015) 'Blue space geographies: Enabling health in place', Health \& Place, 35, pp. 157-65. doi: 10.1016/j.healthplace.2015.07.003.

Forsyth, I. et al. (2013) 'What are surfaces?', Environment and Planning A, 45(5), pp. 1013-1020. doi: 10.1068/a4699.

Garrett, B. L. (2010) 'Videographic geographies: Using digital video for geographic research', Progress in Human Geography, 35(4), pp. 521-541. doi: 10.1177/0309132510388337.

Glover, T. . and Parry, D. (2009) 'A third place in the everyday lives of people living with cancer: Functions of Gilda's Club of Greater Toronto.', Health \& Place, 15, pp. 97-106.

Gorman, R. (2017) 'Health \& Place Smelling therapeutic landscapes: Embodied encounters within spaces of care farming', Health \& Place, 47, pp. 22-28. doi: 10.1016/j.healthplace.2017.06.005.

Grasseni, C. (2004) 'Video and ethnographic knowledge: Skilled vision in the practice of breeding', in Pink, 
S., Laszlo, K., and Ana, I. A. (eds) Working Images: Visual Research and Representation in Ethnography. London: Routledge, pp. 15-31.

Hine, R., Peacock, J. and Pretty, J. (2008) Care farming in the UK: Evidence and Opportunities. London: NCFI.

Kearns, R. (2014) 'The health in "life's infinite doings": a response to Andrews et al.', Social Science \& Medicine (1982), 115, pp. 147-9. doi: 10.1016/j.socscimed.2014.05.040.

Kindon, S. (2003) Participatory video in geographic research : a feminist practice of looking ? Area, 35(2), pp, 142-153.

Kindon, S. (2016) Participatory video's spectro-geographies. Area, 48(4), pp. 449-451.

Lorimer, J. (2010) 'Moving image methodologies for more-than-human geographies', Cultural Geographies, 17(2), pp. 237-258. doi: 10.1177/1474474010363853.

McHugh, K, E. (2000) 'Inside, outside, upside down, backward, forward, round and round: a case for ethnographic studies in migration', Progress in Human Geography, 24(1), pp. 71-89.

Milligan, C. and Bingley, A. (2007) 'Restorative places or scary spaces? The impact of woodland on the mental well-being of young adults', Health \& Place, 13(4), pp. 799-811.

Milne, E, J., Mitchell, C., de Lange, N. (2012) Handbook of Participatory Video. Blue Ridge Summit: AltaMira Press.

Wilson, S, \& Milne, E,J. (2016) 'Visual activisim and social justice: using visual methods to make young people's complex lives visible across 'public' and 'private' spaces', Current Sociology, 64(1), pp. 140-156.

Mitchell, D. and Synder, S. (2000) Narrative Prosthesis: Disability and the dependencies of discourse. Michigan: The University of Michigan Press.

Mitchell, C., de Lange, N. and Molestane, R. (2014) Me and my cellphone: constructing change from the inside through cellphilmsand participatory video in a rural community. Area 48(4), pp. 435-441.

Power, A. and Hall, E. (2017) 'Placing care in times of austerity', Social \& Cultural Geography,19(3), pp. 1470-1197.

Pink, S. (2001) Doing Visual Ethnography: Images, Media and Representation in Research. London: Sage Publications.

Pink, S., Leder Mackley, K. and Morosanu, R. (2015) 'Researching in atmospheres: video and the "feel" of the mundane', Visual Communication, 14(3), pp. 351-369. doi: 10.1177/1470357215579580. 
Pitt, H. (2014) 'Therapeutic experiences of community gardens: putting flow in its place', Health \& Place. Elsevier, 27, pp. 84-91. doi: 10.1016/j.healthplace.2014.02.006.

Pratchett, M. (2012) 'Capturing craft: Employing video ethnography to capture more-than-human craft assemblages of taxidermy practice', in Bates, C. (ed.) Video Methods. London: Routledge, pp. 71-94.

Prosser, J. and Loxley, A. (2008) ESRC National Centre for Research Methods Review Paper: Introducing Visual Methods. NRCM. Available at: http://eprints.ncrm.ac.uk/420/1/MethodsReviewPaperNCRM010.pdf [accessed on 4th April 2014].

Simpson, P. (2014) 'A soundtrack to the everyday: street music and the production of convival healthy public spaces', in Andrews, G. and Kearns, R. (eds) Soundtracks of wellbeing in popular music. London: Ashgate Publishing.

Sitter, K. C. (2015). Participatory video analysis in disability research. Disability \& Society, 30(6), 910-923. https://doi.org/10.1080/09687599.2015.1057319

Spinney, J. (2015) 'Close enounters? Mobile methods (post) phenomenology and affect. Cultural Geographies, 22(2), 231-246.

Trena, M., Paulus, J. and Dempster, P. (2014) 'Analysing Image, Audio, and Video Data', in Trena, M., Paulus, J., and Dempster, P. (eds) Digital Tools for Qualitative Research. London: Sage, pp. 141-163.

Walsh, S. (2016) Critiquing the politics of participatory video and the dangerous romance of liberalism. Area 48(4), pp. 405-411.

Williams, A. (2002) 'Changing geographies of care: employing the concept of therapeutic landscapes as a framework in examining home space.', Social Science \& Medicine, 55, pp. 141-154. Available at: http://www.ncbi.nlm.nih.gov/pubmed/12137183.. 